\title{
Engaging the Adaptive Subject: Learning Evolution Beyond the Cell Walls
}

\author{
Ramsey Affifi ${ }^{1}$
}

Received: 2 August 2019 / Accepted: 2 February 2020 / Published online: 24 March 2020

(c) The Author(s) 2020

\begin{abstract}
According to the modern synthesis (MS), evolution is the gradual change of gene frequencies in a population. The MS is closely allied to adaptationist explanations of phenotypes, where organismic form and behavior is treated as previously selected for and owes its genesis to some remote past. However, some new theories of evolution broadly aligned with the extended evolutionary synthesis (EES), in particular developmental plasticity theory and niche construction theory, foreground the fact that evolution is sometimes much more rapid than previously imagined, and occurs through the active engagement of organisms accommodating and modifying their environments. This article describes how these contemporary theories reveal two interconnected sides of being an adaptive subject, a situated agent that modifies itself and its environment as it lives, and contributes to evolution in turn. MS and adaptationism have a generic logical structure that can be taught anywhere, but because developmental plasticity theory and niche construction theory point to an ontology that foregrounds the agency of the organism, they benefit from in situ exploration. I argue biology as a subject needs to adapt, and call for the renewed importance of field studies, outlining some elements of how such studies might be conceived. I close by considering how understanding organisms as adaptive subjects of evolution has important implications for sustainability education.
\end{abstract}

Keywords Biological agency $\cdot$ Developmental plasticity theory $\cdot$ Niche construction theory $\cdot$ Outdoor learning $\cdot$ Sustainability education

\section{Introduction}

Millions of biology students have been taught the view (from population genetics) that "evolution is change in gene frequencies." ... This view forces the explanation toward mathematics and abstract descriptions of genes, and away from butterflies and zebras .... The evolution of form is the main drama of life's story, both as found in the fossil record and in the diversity of living species. So, let's teach that story. (Carroll 2005, p. 294)

This is one of a series of occasional accounts of educational and other initiatives bridging philosophy of biology and the broader society that we will be publishing in Biological Theory.

Ramsey Affifi

Ramsey.Affifi@ed.ac.uk

1 Institute for Education, Teaching and Leadership, University of Edinburgh, Edinburgh, UK
The standard version of evolution Carroll describes is known as the modern synthesis (MS). The MS emerged as a powerful conceptual integration of Mendelian inheritance and Darwinian natural selection, via statistical reasoning provided by population genetics (Mayr and Provine 1981). The theory depended on a mechanism for inheritance, for novelty, and for spread. Mendelian genetics was identified as the mode of inheritance needed to ensure Darwinian descent with modification, randomly mutated genes of small effect were seen as the cause of evolutionary novelty, while populational studies investigated the ways inherited genes could spread (or not) within a population. Key to the synthesis was the acceptance of the Weismannian barrier, which asserted no environmental influences shaping development could be transmitted to an organism's germline. The result was a conception of evolution that rendered development and the phenotypic organism largely irrelevant for evolutionary studies (Walsh 2015). MS is taught as the primary explanation of evolution in school science curricula (McVaugh et al. 2011; Lehrer and Schauble 2012) and in my experience 
versions of it are also taught by many outdoor and environmental educators.

When the qualitatively abrupt discontinuities revealed in studies of Mendelian heredity became well known to biologists, they were initially thought to present a challenge to the long and gradual nature of change hypothesized in Darwinian evolution, which depended on the accumulation of beneficial micromutations over long periods of time (Bateson 1894). A group of mathematically trained biologists worked out that the two were not in fact dissonant when studied at the population level (Fisher 1918; Haldane 1927; Wright 1932). The focus of their work, which culminated in the MS, examined how random heritable variations get passed on, spread, or diluted in large breeding populations. At the time, genes were considered hereditary factors associated with phenotypic traits. When molecular biology rose to prominence, biologists struggled to map these allegedly phenotypic genes with actual material entities in the genome. This was because individual coding sequences in the DNA rarely had specific, context-independent phenotypic expression (Moss 2003). The Modern Synthesis itself had to evolve to incorporate the dynamics of the newly discovered molecular genes in populations instead of the Mendelian phenotype-associated genes. The result was a gene-selectionist approach to evolutionary theory, developed initially by Hamilton (1964) and Williams (1966), and popularized by Dawkins (1976). The phenotype was seen as too messy and contingent, and the adaptationist logic could more easily be applied to genes themselves, which were now seen as heritable, mutating and replicating entities conceived to behave in a much more "Darwinian" way than organisms (Dawkins 1982). While more recent genomic studies are less atomistic, incorporating noncoding regulatory regions of DNA into their analysis, the result is the same. The organism has fallen out of focus, treated as an epiphenomenon or irrelevance, or as a mere vehicle for the causally efficacious DNA elements, with the evolutionary change occurring at the biochemical level.

In emphasizing interactants and histories not immediately observable, the MS also effectively took evolutionary study indoors. According to the MS, the main players in evolution are microscopic genes or gigantic abstract populations (Walsh 2015). Neither can be directly perceived in the world. Meanwhile, the temporal context of important events in evolutionary process are almost always deferred to the remote past. Contra Darwin and his contemporaries, who were avid naturalists studying real organisms in real contexts, the practice of evolutionary theory became an increasingly decontextualized discipline to be studied through microscopes, mathematical formulas, and computer simulations. The outdoors was swept from theory, and with it the zebras and the butterflies from education about evolution. As this was unfolding, field studies, zoology, botany, and natural history were increasingly replaced in universities by courses on biochemistry, genomics, and molecular biology. Biology became just another sort of indoor chemistry.

Those few who still do teach natural history outdoors have not escaped the lure of MS reasoning. Even when the form and function of species is discussed in less formal educational contexts such as interpretive centers, in my experience adaptationist explanations influenced by the MS clearly dominate. Adaptationist explanation stems directly from Darwin's (1859) most famous insight into the nature of biological evolution. According to Darwin, diversity in a population of organisms implies varying degrees of fitness. The "selection pressures" in the population's environment ensure that not all will be able to reliably or equally pass on their traits to their descendants. Those that do thrive and reproduce will gradually increase the prevalence of beneficial traits in the population. Over many generations, certain stable forms, functions, and behaviors are thought to emerge in a species and persist because the selective regime has not changed. While Darwin was a pluralist when it came to evolutionary mechanisms, adaptationism alone fit the neat logic of the MS paradigm. In keeping with this logic, it is common to hear an environmental educator offer an explanation such as: "this species has trait $\mathrm{X}$ because $\mathrm{X}$ provided a selective advantage to it. It was able to breed and pass on more of the genes that produced $\mathrm{X}$ and outcompete those which did not have it." The efficient cause of the trait is deep in the genes, its origin deep in the past. As I see it, one of the crucial reasons for this deferral is a pervasive conflation of a historical and an ahistorical conception of the term "adaptation" in its use in biology (Kampourakis 2013). According to this author, biology teachers use the word adaptation to refer to both a trait that is the product of prior natural selection, and to refer to the survival advantage a trait confers to an organism in current environmental conditions. When conflated, one comes to implicitly assume the relationship between the organism's current traits and environment is merely replaying an already established correspondence. There is, consequently, no commonly accepted term to even talk about beneficial responses an organism learns or produces during its ontogenic history of interactions with its environment. Whatever might be going on for the first time in the organism interacting with its environment is backgrounded in thinking and blinded from sight.

The result is that in both formal biology curricula and informal environmental education contexts, the organism is inevitably presented as scarcely more than the mindless product of a mindless process. This turns out to be crucial for sustainability education because the concepts used to explain the natural world have consequences on people's affective engagement with the world and thereby their actions towards it (Larson 2014). I suggest that interpreting the organismic behavior and interactions as a mindless process fails to 
invite adequate sympathy for other species or admiration and care for the ecological processes they create. At best, it facilitates simplistic approaches to ecological problems, such as technological solutions that treat organisms as reliable producers of specific outputs: trees planted to sequester certain amounts of carbon dioxide, pigs genetically altered to produce less methane, or predators introduced to control pest populations. At worst, such an approach contributes to a strong form of human exceptionalism that might further exacerbate destructive human activity. Adaptationist explanations tend to attenuate an ontological difference between humans, as free experiencing subjects and agents, and other species, as objects with behavior caused by the interaction of components selected for and integrated in a distant past. Considering other species as adapted objects may be methodologically fruitful for certain purposes (e.g., Godfrey-Smith 2001), but one side effect is it tends to reify the problematic mind/matter split along human/other species lines. Given that up to a million species are currently threatened with extinction (Tollefson 2019), science educators need to urgently address how conceptual frames reify patterns of harmful behavior. Evolutionary theory can and should bridge biology and people's affective lives, a point that will be explored later in the article.

If MS and its bedfellow adaptationism were empirically adequate, in the sense that most organism traits and behavior could be explained through them (see "empirical adaptationism," Godfrey-Smith 2001), it would be an important question whether we should modify how we teach about evolution for the purposes of averting destructive attitudes towards other species. Suppose two evolutionary explanations offer exactly the same predictions but lead to very different conceptions and emotions about humans and their place in the world. In such a case, scientists often appeal to Occam's razor, an aesthetic criterion, to settle what explanation we should adopt. I believe a more ecologically benign theory, i.e., one with more ecological adequacy, should hold its weight against a neater, simpler, or more familiar theory of identical empirical or methodological value. ${ }^{1}$ The 21 st century requires a broader palette of criteria to assess, quite literally, the viability of explanations. Regardless, an increasing body of empirical evidence and theoretical advances suggest adaptationism's explanatory scope is

\footnotetext{
1 The situation gets more complicated when a theory has more ecological adequacy but less (or very slightly less) empirical adequacy. For example, should we settle for a theory that has less predictive power but which leads to behavior that sustains the life support systems we depend upon? If so, in what conditions do we adopt such a theory, and when do we not? Moreover, if this implies a need for theoretical pluralism, how should we teach a pluralistic approach to scientific explanations? We need to develop pragmatic nuance in our thinking, asking what level of accuracy is needed, for what purposes, and to what effects.
}

limited and a much larger suite of evolutionarily significant influences need to be considered in explaining the emergence of observable traits and behaviors. I will briefly discuss how some significant supplements and disruptions to modern evolutionary theory, sometimes rallying under the term "extended evolutionary synthesis" (EES) (Pigliucci and Müller 2010; Laland et al. 2015), transform the adaptationist argument. While not all EES approaches invite the need for outdoor learning provision, many do. I will focus on two influential and connected concepts: developmental plasticity (West-Eberhard 2003) and niche construction (Lewontin 1983; Odling-Smee et al. 2003). These concepts turn out to be very intuitive (much more so than the logic of Darwinian evolution) and more aligned with a pedagogical orientation aiming to acknowledge and appreciate the subjectivity (in Godfrey-Smith's 2017 sense, see below) of other species. To be more precise, I hope to show that these concepts unify, revealing organisms as adaptive subjects rather than merely adapted objects. On the basis of such concepts, I argue for the need to take learning about evolution out beyond the cell wall: literally beyond the causally inflated DNA and into its larger contexts, but also figuratively beyond the confines of the classroom and into the real world where organisms can show their prowess, inventiveness, and ongoing contributions to the diversity of the world.

\section{The Extended Evolutionary Synthesis (EES)}

In recent years, accumulating theoretical developments and evidence suggest the adaptationist framework of the MS is an insufficient model for evolutionary process, and alternative approaches are gaining steam. Though still a disparate set of methodological and theoretical approaches, a promising new interdisciplinary research program has emerged. Some scholars seek to draw these threads together under the possible banner of EES (Pigliucci and Müller 2010; Laland et al. 2015; Müller 2017), while others believe a more radical dismissal of natural selection and its associated ontological commitments is needed (Depew and Weber 2011; Walsh 2015). I shall not attempt to settle that debate here, but instead review some of the main currents within this emerging nexus of research programs.

An early critique of adaptationism put forth by Gould and Lewontin (1979) suggested that given the basic physical properties of biological systems, much of the form (and probably behavior) of the organism were likely by-products of other adaptive characteristics or morphological necessities (this latter possibility was pursued early on by D'Arcy Wentworth Thompson 1942). This idea has developed into several influential research programs (e.g., Goodwin 1997; Müller and Newman 2003; Arthur 2004). According to these authors, we misunderstand biology when we seek adaptive 
explanations for every trait. ${ }^{2}$ Gould and Lewontin's (1979) paper gave rise to a more cautious consideration of species traits and the explanations we give of them, which has spawned fertile areas of research both within and outside the MS. Given some trait, how would we know whether it evolved for adaptationist reasons, emerged out of some ontogenetic necessity, or simply emerged by evolutionary drift? ${ }^{3}$

More recently, a blossoming of diverse theoretical approaches to understanding evolution have come forth. These include EvoDevo theory (Müller and Newman 2003; Carroll 2005; Kirschner and Gerhart 2005; Gilbert et al. 2015), multiple inheritance theory (Jablonka and Lamb 2005), symbiotic theory (Margulis 1993; Gilbert et al. 2012), multilevel selection (Wilson 2010), phenotypic and developmental plasticity (West-Eberhard 2003; Pigliucci and Boudry 2010), the evolution of evolvability (Wagner and Altenberg 1996; Wagner 2007; Pigliucci 2008), the evolution of gene regulatory networks (Davidson 2006; Shapiro 2011), and niche construction (Odling-Smee et al. 2003).

After giving a brief overview of these concepts, this article will consider educational implications of developmental plasticity and niche construction theory. EvoDevo is the examination of how evolution and development mutually affect one another such that an explanation of one is not possible without appealing to the other. An amendment of it, known as EcoEvoDevo, seeks to articulate the feedback loops between evolution, development, and ecology (Gilbert et al. 2015). Multiple inheritance theory is the idea that, in addition to genetic inheritance, there are many other evolutionarily significant factors that are passed on to further generations through (for example) epigenetic modifications to the genome, behavioral and parental effects, inherited niches, and inherited symbiotic communities (Jablonka and Lamb 2005). Symbiotic theory discusses how speciation and other important evolutionary processes are dependent upon or influenced by changes in microbial symbiosis (Gilbert et al. 2012). Multilevel selection examines whether and how adaptationist arguments can be employed to understand evolutionary processes at different scales (from the gene, to organisms, to group selection) and how these levels interact

\footnotetext{
2 According to Dennett (1995), such critiques are levelled at strawmen because no one would seek to explain adaptationally why an elephant has more legs than eyes. As Dennett sees it, it is easy for MS and neo-Darwinism to incorporate such critiques: the morphospace of possibilities for natural selection is not continuous. It is filled with many holes, genetic and morphological regions that simply cannot be filled.

${ }^{3}$ Moreover, in what ways can organisms subsequently utilize nonadapted traits for adaptive purposes, in a process some evolutionists call "exaptation" (Gould and Vrba 1982)? In a particular case, how could we find any of this out? And what learning contexts and environments best assist learners in doing so?
}

(Wilson 2010). Phenotypic and developmental plasticity is a subset of (Eco)EvoDevo focused on how organisms' development produces evolutionarily significant novelty that can later (through non-Lamarckian means) get genetically encoded (West-Eberhard 2003). The evolution of evolvability is concerned with the processes and mechanisms whereby variations in versatility at the genetic and other levels become themselves regulated (Wagner and Altenberg 1996; Wagner 2007). The study of gene regulatory networks involves an examination of the varying ways genes become mutually implicated in phenotypic outcomes and also how gene expression is directed by the cellular and organismic behavior (Shapiro 2011). Finally, niche construction theory considers the many ways organisms actively and passively modify their environments and thereby change the selection pressures that affect them and other species in their ecological communities (Odling-Smee et al. 2003).

The reader will observe that some of these approaches are more amenable to adaptationist arguments than others. For example, the evolvability of genetic code can be considered in relation to the adaptiveness of genetic variance, where too much (or too little) genetic variability leads to decreased viability and therefore fitness. Nevertheless, it should be clear that even in this case, a warning is issued for the educator keen to elicit off-the-cuff adaptationist hypotheses about observable traits: particular behaviors or traits observed cannot be assumed to have been the consequence of prior evolution. It may well be the organism's capacity to produce these behaviors in response to environmental circumstances that was selected for. This capacity is of course invisible in field studies.

In the next two sections, I will consider developmental plasticity and niche construction in greater detail because they exemplify the different methodological and ontological commitments underpinning current evolutionary explanations. They also provide clear opportunities for outdoor educators to engage students in understanding, exploring, and participating in their biological worlds, as will be discussed later in the article.

\section{Developmental Plasticity Theory}

The developmental plasticity approach to thinking about evolutionary novelty is most closely associated with the work of West-Eberhard $(2003,2005)$ and Kirschner and Gerhart (2005), among others. As noted above and elaborated upon here, this approach foregrounds the role that the organism plays in negotiating its environments, and the import this role has on evolution. In so doing, it acknowledges observable macroscopic variations, such as atypical form and behavior, as potentially significant evolutionary novelty. Organisms are seen as causal actors, or agents, in the production of 
new form and behavior (Walsh 2015). According to the logic of developmental plasticity theory, once beneficial novelties are produced, natural selection then works on tweaking the regulatory genes that facilitate the reappearance of these new features. This reversal makes genes often the followers rather than the leaders in evolution (West-Eberhard 2003, 2005). As we shall see, as opposed to gene-centric approaches that increasingly conduct research in laboratories, developmental plasticity theory implies field investigation as an important method to witness such evolution in action.

West-Eberhard (2003) defines developmental plasticity as the change(s) an organism makes to its form, state, movement, or the rate of its activity in response to its external and internal environments (2003, pp. 32-33). Her conception is very general and encompassing, as it includes "active and passive, reversible and irreversible, and continuous and discontinuous responses" (2003, p. 36) under that single term. The educational significance of each shall be briefly discussed in the paragraphs that follow. For West-Eberhard, the plastic possibilities of a phenotype are not to be taken as a range of options preprogrammed by a genotype (which would slide into gene-centered adaptationist logic). The first reason for this is developmental: the phenotype (such as the egg cell) precedes the genotype and itself already conditions how and when DNA will be translated and transcribed based on its structure and context. A bottom-up causal explanation of organismic development not only fails to capture this reciprocal determination between the organism phenotype and genome, it also ignores the fact that genomes are only causally efficacious as information when situated in information-constituting developing phenotypes (Oyama 2000), which is why DNA outside of its cellular context is inert (Noble 2015). A second reason is ecological: environments are very dynamic and themselves evolving in complex ways, so it is unlikely that all seemingly adaptive traits and behaviors in a given organism are purely the result of prior selection.

Before going on, it is useful to clarify some elements of West-Eberhard's definition. The first point is her insistence that plasticity is a response to internal and external environments. For West-Eberhard, as for others working within evolutionary developmental biology, the genome is considered to be part of the organism's environment. This would seem incongruent from a gene-centrist ontology, but it asserts the system-level importance of the organism as a whole. Without this, it is difficult to understand how an organism turns on and off certain genes or alternatively splices genes to different effects in response to factors that it as a whole is dealing with. A second advantage is that factors in the external environment and those in the internal environment have causal parity in how they influence the organism and in how the organism adapts or refashions these factors to suit its needs (Oyama 2000). Instead of the organism conceived as the by-product of a genetically determined system modulated by an environment, it is seen rather as a system regulating and responding to contingencies within and outside of itself. The most memorable example West-Eberhard gives in illustration of this process is a domestic goat born with only two legs. The goat accommodated this abnormality through a coordinated series of anatomical, physiological, and behavioral changes. It walked in upright posture and developed very particular muscular and skeletal specializations, manifesting in its integration similarities with a kangaroo's morphology including an elongated neck (2003, pp. 51, 52). For West-Eberhard, phenotypic changes induce changes in gene regulation and expression too, ${ }^{4}$ which in turn facilitate phenotypic accommodation (2003, p. 147). In some sense, it does not matter at what level the initial novelty arose, be it through genetic abnormality, fetal chemical exposure, or through having its legs amputated at birth. In any case, phenotypic changes are coordinated and systemic, inducing cascades of responses within and without. Morphological plasticity is driven by behavioral plasticity, which is itself a goal-oriented organismic activity.

West-Eberhard's refusal to distinguish between active and passive plasticity is a direct consequence of this position. Williams (1992a) argued that things like tree branches breaking in the wind and babies' heads changing shape as they pass through birth canals are passive modifications, by which he means mere susceptibilities to influence. Because no metabolic or physiological work goes into these phenotypic changes, Williams asserts it is misleading to think of these as plasticity. West-Eberhard refuses this distinction on several important grounds, ${ }^{5}$ one of which is particularly relevant for educators working in the outdoors. Even if it is possible to imagine a passively acquired trait, it will not stay passive for long. Take the two-legged goat as an example. As it ambles around the field, its morphology coherently connecting together into a functional gait, we might ask: what part of its behavior was acquired passively and what part was an active readjustment? In many cases, an organism might exacerbate the difference between it and more species-typical organisms as it learns to live. Organisms transform themselves to render potentially deleterious traits more viable. Exaptation (Gould and Vrba 1982) is in this sense a developmental process. This is a crucial point for educators because it means atypical variation is largely the

\footnotetext{
${ }^{4}$ Shapiro (2011) has convincingly shown somatic cell DNA effectively functions as a read-write storage system.

5 As she sees it, Williams is attempting to smuggle adaptationism back into his explanatory framework because all allegedly genuine plastic responses are seen to have been evolutionarily selected for in that organism's ancestral history. In other words, he wants to pull in a repertoire of available programmed responses that would not allow for contingent adaptive novelty.
} 
product of capacities rather than mutated programs, and of resilience rather than determinism.

The second dualism developmental plasticity theory challenges is between reversible and irreversible plasticity. Stearns (1989) suggested the word "plasticity" be confined to discussions of irreversible responses to the environment, while the term "flexibility" be employed for cases where new behavior or form can be extinguished as necessary. The twolegged goat is an example of an irreversible response, while the folding leaves of a Mimosa pudica plant can be seen as reversible insofar as they reliably return to normal. However, whether or not a trait is reversible is a somewhat subtle issue. Many allegedly reversible behaviors do not, strictly speaking, put the organism back to some prior baseline of its development. The fact that the organism has produced a response to its environment bears its mark anatomically and physiologically, evidenced when subsequent interaction with that stimulus leads to changes in the rate, strength, or type of response. Indeed, there is evidence $M$. pudica habituate leaffolding behavior when an atypical though harmless stimulus is repeatedly applied to them (Gagliano 2014). ${ }^{6}$ Outside of gulls, crows, and squirrels, in many temperate contexts habituation is not easy to identify outdoors because most organisms that habituate quickly (i.e., animals) appear but fleetingly, while sessile organisms (such as fungi and plants) will normally respond within a time frame unusable in most education contexts. Nevertheless, habituation demonstrates the ubiquity of plastic responses across the biological world. It is useful to invite students to think about whether or not the behavior of organisms they experience outdoors are "genetically determined," habituated, or both, and what that difference might mean.

Finally, the difference between continuous and discontinuous variation is also seen as misleading because it posits another distinction in kind that can be adequately explained through similar underlying processes. Continuous variations are seen as graded responses (such as skin tanning or acclimatization) whereas a discontinuous response is taken to refer to qualitative jumps in the behavior or form of the organism (such as polyphenisms and some types of learning). Though not essential to the argument of this article, I will point out in passing that threshold points mediate whether or not a response is continuous or discontinuous, but such threshold points are themselves also subject to various environmental influences (which may also have their

\footnotetext{
6 The experiment consisted of a controlled drop system that would safely slide potted mimosa plants down a shaft. Gagliano et al.'s intention was to repeatedly subject the plants to a treatment that induces a response but which is clearly nonadaptive in that it is ecologically unlikely to occur. For my own part, I noticed $M$. pudica near the side of well-trodden paths are less likely to fold their leaves and discussed it anecdotally (see Affifi 2011).
}

own threshold points; see West-Eberhard 2003, Chap. 5). As for the prior discussions about activity and reversibility, there is no simple correlation between whether or not a response is continuous and whether or not it is adaptive.

Connecting back to our main discussion, it is worth summarizing that from a developmental plasticity theory perspective, it is difficult to make any a priori statement as to whether a particular trait is the adapted product of past selection, a malfunction or irrelevant side effect of some process or interaction (see Griffiths 2008), or a developed adaptive response to contingently lived situations. Even species-wide features merely reflect the fact that during development certain environmental variables are so constant and predictable organisms reliably reinvent stereotypical responses that therefore appear to be genetically programmed (Oyama 2000). In other words, in taking a systems theoretic view, developmental plasticity theory resists the idea of preformationist genetic information residing in the genome in favor of the notion that information is constructed by the organism during its ontological development (see Oyama et al. 2001).

From the developmental plasticity theory perspective, in what sense are genes said to be followers rather than leaders in evolutionary novelty? At face value, this seems to resurrect the notion of inheriting acquired traits, an idea proposed by Lamarck (1809) and routinely ridiculed through most of the 20th century. "Lamarkism" has been considered heretic as it defies the impermeability of the Weismannian barrier (see above), which states the germline is sequestered from the somatic line, so information cannot pass from the body back into the sex cells. ${ }^{7}$ But plasticity theorists do not usually rely on neo-Lamarckian mechanisms to support their notion that acquired novelties eventually get encoded in the genetic inheritance of the organism. One mechanism, known as "genetic assimilation," suggests that plasticity enables organisms to buy time, with stochastic gene variation catching up later on to automatize the beneficial novelty with less energetic burden (Waddington 1953; Goldschmidt 1940; Schmalhausen [1949]1986; see Schlichting and Wund 2014). Another view focuses on the immediate microevolution conferred by plasticity, noting organisms more able to plastically accommodate their environments are more likely to produce offspring, leading to the increased prevalence of

\footnotetext{
7 Such a view clearly takes an animal-centric bias when describing evolutionary process (in plants and fungi, sex cells emerge out of mature somatic cells, while bacteria directly pass their acquired genes to each other through horizontal gene transfer). However, even in animals, gametes are not originally separated. For example, prior to oocytogenesis, there is a developmental period during which the somatic cells undergo environmental influences. There is also accumulating evidence indicating the extent to which epigenetic changes to the genome are passed on (Jablonka and Lamb 1999, 2005; Gissis and Jablonka 2011). These include methylation, chromatin changes, and histone modifications.
} 
genes that allow such modifications to flexibly arise again in the next generation. For West-Eberhard, "genetic accommodation" follows "phenotypic accommodation." A beneficial plastic response is generated more or less automatically in future generations not primarily through the subsequent evolution of entirely new genes, but through the tweaking of existing ones that regulate the threshold for such a plastic response (West-Eberhard 2003). As should be clear from these examples, the organism is thereby instated as a causally significant contributor to the ongoing process of adaptive evolution.

As educators, we might therefore follow William Bateson's advice and treasure the exceptions we find to typical species phenotypes (Cock and Forsdyke 2008). But to treasure them, we must first of all be able to witness them and this is where the outdoors comes in as a crucial space to observe moments of potential evolutionary significance. A given trait may not be adapted in the sense of having been vetted through a prior evolutionary history. But it may become adaptive, in Kampourakis' (2013) second sense described above, insofar as that organism is trying out, inventing, or stumbling upon novel possible means of accommodating its diverse environments that may later become increasingly mechanized. An educator might provoke such thinking in their students by asking them to observe carefully and hypothesize whether some atypical feature may or may not be adaptive in this sense. The presence of traits and behaviors that seem to functionally assist the organism is not necessarily an indication that these traits have been determined. Species-typical behavior is a statistical construction and few in a given population may actually behave prototypically, while some may be significant outliers. These variations may be crucial to evolution even if they are not (yet) the result of underlying genetic differences. Population sampling is an effective way of seeing differences within phenotypes within a species, but in our case it is carried out with a very different purpose than to merely seek out generalities. In other words, sampling can be carried out for nomothetic and idiographic ends, the latter aiming to identify and study the emergence of particular and unique cases.

After discussing our second important concept, niche construction and the relationship between it and developmental plasticity, I will review how this changed understanding of the organism has important implications for articulating and conducting naturalistic fieldwork in outdoor education settings.

\section{Niche Construction Theory}

Standard MS models assume an organism's environment changes so slowly that it can be treated as a constant. According to this view, the phenotypic expression of the genome is tested for viability against a relatively steady ecological context, and adapted organisms are seen to have inherited traits fit for pre-established niches. ${ }^{8}$ In the voice of one influential proponent, "adaptation is always asymmetrical; organisms adapt to their environment, never vice versa" (Williams 1992b, p. 484), a view known as explanatory "externalism" in evolutionary theory (Godfrey-Smith 1996). Following population geneticist Lewontin (e.g., 1983), scholars produced an alternative view acknowledging the dynamic role of the organism in shaping its environment, and the significance of this as an evolutionary process. Much of this work constellates around the term "niche construction" which can be defined as "the process whereby organisms, through their metabolism, their activities, and their choices, modify their own and/or each other's niches" (Odling-Smee et al. 2003, p. 419). Niche construction theorists assert that niche construction modifies environments in ecologically and evolutionarily consequential ways, with effects on natural selection (Odling-Smee 1988; Turner 2000; Odling-Smee et al. 2003; Laland et al. 2016). ${ }^{9}$ Empirically, this phenomenon has been observed and modelled in the field (Laland et al. 1996, 1999; Kerr et al. 1999). Niche construction theory leads to a number of different consequences which, like developmental plasticity theory, foreground organisms as systems theoretic agents in evolutionary processes.

While the focus of MS is often on the evolution of organisms, niche construction theory concentrates explicitly on the coevolution of organisms and their environment. Because organisms modify their external environments through living, there is no fixed "selective environment" (Brandon 1990) vetting organisms as externalists presume. To varying degrees, organisms change and in part determine the selection pressures affecting them (Odling-Smee et al. 2003). Organisms tend to alter their selection pressures in directed ways that benefit their survival, and this accounts for some of the complementarity we observe between

\footnotetext{
${ }^{8}$ In adaptionist explanations, it is important that the context is seen as constant precisely because the evolutionary mechanisms (gradual stochastic genetic micromutations selected for by relatively constant environmental pressures, or drifting due to a relative lack of such pressures) are assumed to work so slowly. Were the environment dynamic in any significant sense, then the gradualistic nature of evolution would be unlikely to ever be an effective cause of existing adaptations. As a result, to protect the viability of the simplifying assumptions behind MS, the ontological relevance of the organism had to be undermined in favor of the theoretical importance of changing genes and their selective environments. This has led to blinkers put up against considering the role that organisms play in adaptively shaping their own and others' environments.

${ }^{9}$ For the purposes of this article, I do not make a distinction between "niche construction" (Odling-Smee et al. 2003) and "ecosystem engineering" (Jones et al. 1994, 1997). See Godfrey-Smith (2017) for a discussion of these two terms.
} 
organisms and their environments. Many of these changes can have transgenerational and cross-species effects when niches are inherited (Badyaev and Uller 2009; Odling-Smee 2010). Finally, niche-construction activities may or may not be adaptations in the Darwinian sense of being traits previously selected for as they confer survival advantage. Some favorable activities may be adaptive because they have been learned, invented, mimicked, or otherwise acquired, a fact pervasive across the biosphere but particularly evident in human culture. Like developmental plasticity theory, niche construction theory also therefore identifies and studies adaptive traits and behaviors in Kampourakis' (2013) second sense. In other words, if developmental plasticity theory tells us organisms are not passive vehicles of acquired units of information (genes), then niche construction theory asserts organisms are also not passive targets of selection (Avital and Jablonka 2000).

Employing the outdoors in understanding niche construction is both easy and imperative. It is imperative because without experiencing the daily activities of actual organisms, one is tempted to ignore what role those activities might have on the world around them. This indeed is just what often happens in MS reasoning. ${ }^{10}$ Employing the outdoors is easy because all organisms are doing things to get by. When biology teachers and environmental educators take learners out into the field to study behavior first hand, they might initiate activities like asking learners to list ways they think a particular tree is affecting its context. Once volatile organic compounds, leaf litter, cellular respiration, tropism, and effects of shading are taken into account, it becomes increasingly obvious that a tree is modifying its environment. For example, shading leads to favoring different plant growth in the adjacent regions. Depending on the particular architecture of the tree, different amounts of light filter into the canopy, which creates a context where the tree is competing and cooperating with a different set of organisms than when it set out as a seedling. And of course, the tree also becomes its own environmental pressure in a more direct sense: the shade it casts upon itself leads it to grow in particular ways.

While these sorts of effects are sometimes labelled "extended phenotypes" according to a gene-centered view of evolution $^{11}$ (Dawkins 1982), gene-centered accounts are incomplete because they simply widen the scope of what is considered the effect of genes without positioning the developing organism as a causal locus in the process. Dawkins' approach is adaptationist because the same logic is applied, just at a broader scale. Resorting to explanations that rely on stable selection pressures in some deep past, this approach de-emphasizes the possibility that the effects of organismic behavior might be the consequence of novel responses generated to emerging contingencies. Through positive feedback, niche construction initiates developmental, ecological, and evolutionary momentum effects, and through negative feedback, dynamic inertia or equilibria in these same interconnected systems (Laland et al. 1996; Creanza and Feldman 2014).

Sometimes niche construction builds up effects over time, leading organisms to inherit niches created by others. Organisms are born into ecosystems that are the product of various organisms engaged in modifying their own selective environments (Odling-Smee 2010). An example of this is worm casts (recognized and described by Darwin in an early observation of this phenomenon), which have compounding effects on soil structure, humidity, and chemistry that alter the viability of the soil system for other species and for subsequent earthworms (Nuutinen 2010). As the worm is modifying the soil, other organisms are doing the same, implying that inherited niches are negotiated and dynamic. However, inherited niches are not always simply physicochemical. Parental care, inherited behavior, and animal traditions are all examples of intergenerational sociocultural niche construction (Avital and Jablonka 2000), and human language is also a semiotic landscape both constructed and passed on (Clark 2006), with similar ratcheting up effects through positive feedback (Deacon 2003) as occurs in other inherited niches. The products of niche inheritance are easily observable in the field but because they are often slow and accumulating, even something dynamic like social niche construction is unlikely witnessed. If the aim is to focus on the organism as a dynamic agent, the educator might take an organism's directly observable environmental modifications as a point of departure and ask whether or not they lead to lasting effects for the various species present.

\footnotetext{
10 More specifically, MS is happy to assert organisms alter their environments, but maintains such changes can be treated as a background condition rather than a source of evolutionary innovation (e.g., Dawkins 1982). If organisms have been previously selected to behave in certain ways, then their environmental influences are themselves stable and predictable and will simply serve as part of the selective environment. This can (and is) studied outdoors, but reduces all organism behavior to the repetitive effects of prior selection. Niche construction can restore the organism as participant and collaborator in evolution, lending intrigue and urgency to studying behavior in field conditions.
}

\footnotetext{
11 According to Dawkins (1982), if genes are the main causal agents that induce upward effects, it is arbitrary to designate the phenotype as merely the body and behavior of the organism. Worm castings, leaf litter, beaver dams, and human technologies would all be seen as part of a broader phenotype.
} 


\section{Unifying Development Plasticity and Niche Construction Theories: Reciprocal Causality and the Adaptive Subject}

At root in both developmental plasticity and niche construction is an issue about the nature of causality. A metaphysics that assumes causality can only be bottom-up, with higherlevel phenomena necessarily and sufficiently explained according to lower-level mechanisms, will not grasp the novelty-generating and causally efficacious processes that emerge from the behavior of the organism itself. While bottom-up explanation can articulate how a system's parts interact to produce an organism, in emergent processes such as living organisms the capacities of those parts exist by virtue of their being integrated and regulated by the organism's activity. This latter phenomenon, sometimes called "downward causation," has been articulated in different ways (e.g., Juarrero 1999; Thompson 2007; Walsh 2015; Godfrey-Smith 2017). Because of downward causation, niche construction is not merely the effect of an extended phenotype. ${ }^{12}$ When niche-constructing organisms sense, integrate, and respond to environmental information, their constructed niche is part of the organism's context that permits, constrains, and regulates gene action. Similarly, its plastic possibilities are not simply a range of available responses preset genetically because these responses reemploy genetic resources to new ends. The integration of mechanical (efficient) causality and downward causation leads to the concept of reciprocal causation (Laland et al. 2012).

Reciprocal causation between an organism and its environments is indicative of a fundamental conceptual shift towards recognizing the developing organism as a subject (Godfrey-Smith 2017). According to this Godfrey-Smith, a subject is an entity that has (1) a point of view on the world and (2) an agenda (2017, pp. 4-5). Having a "point of view" means an organism is sensing and integrating information from a situated spatiotemporal location. Having an "agenda" means the organism acts in response to this information to further its needs. While it might be tempting to categorize these two aspects as something like "sentience"

\footnotetext{
12 For some niche construction theorists, phenomena that can be legitimately considered extended phenotypes are niche constructions, but not all niche constructions are extended phenotypes. For instance, according to Laland et al. (2016), niche construction theory accepts acquired behavior as a cause and does not attribute all construction activity to the direct or indirect expression of genes. It also recognizes how positive feedback creates inherited niches. These are not accepted in extended phenotype explanations. From a developmental systems theory point of view (Oyama, see the third section) and the view promoted in this article, the concept of an extended phenotype would be even less defensible. While it might describe some phenomena, it does not adequately take into account the shift in causality that arises in organic systems.
}

and "behavior," both aspects of Godfrey-Smith's subjectivity are fundamentally interconnected. On the one hand, sensory organs are not passive (Dewey 1963). They actively track relevant environmental features. On the other, ongoing activity is continuously sensed and fed back to the organism (for example, in animals this occurs through proprioception). More shall be said about Dewey's analysis shortly. For now, it is sufficient to understand how Godfrey-Smith's description of the organism as a subject helps articulate how it enables and sustains reciprocal causation between itself and its interactants.

The concept of niche construction emerged from population genetics rather than developmental biology, and has a correspondingly different emphasis. Nevertheless, both developmental plasticity and niche construction are in many ways complementary descriptions of an organism-centered view of life. It is increasingly acknowledged that "to develop is to interact with the environment" (Schwab and Moczek 2017, p. 4; emphasis added). This insight has led to attempts to combine developmental plasticity and niche construction theories. Both seek to replace the linear causality assumed in gene-centric models with one of reciprocal causation constituted through ongoing feedback loops between organisms and their environments (Laland et al. 2008). Phenotypic modifications and changed ecological relations are inseparable aspects of a single integrated dynamic.

While evolutionary developmental biologists focus more often on an organism's plastic responses to its environment, niche constructionists focus instead on an organism's effects on its environment. However, as Laland et al. (2008) point out, many in both research programs refuse to draw sharp lines (see, for example, Lewontin 1983; Oyama et al. 2001; West-Eberhard 2003; and Jablonka and Lamb 2005). A particularly fruitful convergence between these two areas is found in recent niche construction work which considers development as the ongoing process of constructing and responding to external and internal environments (Laland et al. 2016; Gilbert et al. 2015). As Laland et al. (2016) summarize, "[i]t can be seen that niches and environments exist inside the body, whilst physiological processes operate outside it" (p. 2420), because organisms actively regulate both their internal and external contexts in ways often biased towards increased viability. However, the integration is even tighter than portrayed here, because a changed external environment will afford different organismic responses, while new behavior will change the external environment in turn (Walsh 2015). ${ }^{13}$

\footnotetext{
13 An additional point of confluence is the fact that developmental plasticity, especially in cases of population-wide responses to environmental shifts, can lead to significant evolutionary impacts by systemically modifying the selective environment.
} 
A similar ontological shift is behind the reasoning of both developmental plasticity theory and niche construction. In each, evolutionary change is seen as instigated and directed by the organism. While MS is wedded to the view that evolutionary novelty arises through random gene changes, developmental plasticity theory claims it is often the result of phenotypic accommodation, and niche construction theory asserts it can be brought about by how an organism actively modifies its environment, which in turn affects it and other species. As adaptive agent, the organism is an effective causal nexus and its drive to survive pushes the evolutionary process forward. In this way, teleological reasoning returns to natural history, not in the sense of fathoming the whim of a transcendent creator (Paley 1809), nor as a heuristic stance (Mayr 1974), but instead as an aspect of how organisms modify themselves and others based on their needs and purposes (Thompson 2007; Walsh 2015). In responding to contingent conditions as opportunities or impediments, organisms innovate life strategies that can become entrenched in the heredity of the organism-environment system, be it in genes, behaviors, or ecological features and their integration. Life leads evolution, coopting genetic resources and altering selection pressures through its cunningness. This ontological shift invites us to consider real organisms negotiating real conditions. It invites educators to get outdoors and start paying attention to what is around them.

Developmental plasticity and niche construction can be thought of as related to one another in a way analogous to the two aspects of Godfrey-Smith's "subject." According to Dewey, the distinction between sensing and acting mentioned a few paragraphs back is made for pragmatic methodological reasons but is not an ontological distinction. However, all of the splits discussed in this section result from taking apart relations established through reciprocal causality and not putting them back together again after analysis. Niche construction theory places more focus on the environmental effects of being a subject and developmental plasticity theory on the responsive side, but these are points of emphasis made for pragmatic reasons rather than on ontological distinction.

According to Godfrey-Smith, the word "agency" foregrounds one half of this two-sided coin, but I believe Walsh's (2015) use of the term captures this Deweyan dynamic, so in this article, I use the terms interchangeably. For Walsh, agency

consists in a capacity of the system to pursue goals, to respond to the conditions of its environment and its internal constitution in ways that promote the attainment, and maintenance of its goal states. Agency is observable in the sense that what we see when we observe an agent is its dynamics, the way that the agent negotiates its situation (2015, p. 210).
As Walsh suggests, this concept of subjectivity or agency is not merely an internal or qualitative phenomenon inaccessible to empirical study, as dualistic notions related to dominant approaches to behaviorism posit and reject (e.g., Skinner 1938). Specifically, an organism's agency is revealed in how it organizes and responds to its ongoing interaction with its internal and external environments. I suggest the word adaptive subject to capture the idea of a subject in the Godfrey-Smith/Walsh perspective, actively contributing to evolutionary processes through engaging in observable adaptive (in Kampourakis' (2013) second sense) activity through constituting reciprocally causal interactions with its inner and outer environments. In the final section of this article, I will sketch out reasons why I think imagining an organism's point of view is an important educational process facilitated by interaction and observation.

\section{Learning Evolution Outdoors}

Putting students into contact with nature can be done in many different ways, from unguided experiences to those mediated in various ways by caregivers, educators, and media. As such, merely asserting that students ought to learn evolution outdoors is broad and possibly miseducative. Approaches are needed that scaffold student current understandings and misunderstandings to the broader purpose of acquainting them with instances that exemplify organisms as adaptive subjects participating in evolution. Constructing such learning opportunities demands knowledge of ecological processes, the affordances of teaching locations, and the thoughtful and skillful involvement of the outdoor educator in maximizing learning opportunities. Teasing out the effects of these encounters is a difficult task, compounded by the potentially contradictory encounters that can occur during a single experience or sequentially. For instance, if students are already habituated to observe other species in typological ways, further observation without appropriate prodding can sometimes actually reinforce their stereotypes. This should be an attractive challenge for a committed educator but will need support through professional pre- or in-service learning opportunities.

If a primary purpose of outdoor learning is to foster a different sort of relationship and understanding of the natural world through sustained interaction with it (Chen-Hsuan Cheng and Monroe 2012; Christie and Higgins 2012; Nazir and Pedretti 2016), it is of critical importance to examine how people mediate these interactions through theory and experience. It is my position that the ubiquitous use of MS explanations does more harm than good by fostering an attitude that collapses the teleology, novelty, and the subjectivity/agency of other organisms. Relying on adaptationist explanations means seeing evolution as something that has 
basically already happened, and the organism as the mindless by-product of biochemical mechanisms selected for long ago. Not only is this an inaccurate account of the actual diversity, contingency, and innovation of the organic world, it is also a destructive premise by which to approach other beings. Outdoor learning offers direct experiences with phenomena that put science back into the immediate sensuous lifeworld of an inquirer. Dewey wrote, "the senses are the organs through which the live creature participates directly in the on-goings of the world about him. In this participation the varied wonder and splendor of this world are made actual for him in the qualities he experiences" $(2005$, p. 22). How might we bring the zebras and butterflies back into splendor?

As suggested in this article, theory and learning context mutually inform one another in various ways. Certain approaches, such as the MS, lead to an increased focus on indoor learning contexts, which in turn can lead to increased "indoor theory" that can be easily created, understood, and explored without spending significant time engaging with the actual processes and interactions one is attempting to describe or explain. On the other hand, even environmental educators working outdoors are susceptible to reproducing dominant MS reasoning in the face of evidence that might reveal its inadequacy. What is urgently needed is a complementarity between agential models in biology and learning contexts that enable students to observe and build upon these understandings.

In this vein, I summarize and expand upon some approaches that might be taken by educators.

- Educators should encourage observation by seeking out differences between cases instead of merely commonalities (for instance, individuals within a population of a given species). One activity might be to encourage students to find cases where organisms do not behave or look like their textbook descriptions (Affifi 2019a, b). Developing such a faculty of observation can be assisted by various arts, such as drawing and painting, which focus the eye and mind on grasping phenomena in their particularity. Gardening is also a way of developing a daily practice to engage with particular organisms as opposed to general abstractions and/or statistical generalities for given species.

- Educators should stimulate students' consideration of how atypical differences may be adaptive, even if atypical for the species (and therefore not necessarily evolutionarily selected). This may be easier with some species than others.

- As an activity, students can sample and survey the range of phenotypic variation within a population for the purposes of developing understanding of how environments allow diversity to flourish, and to counteract the idea that natural selection (and/or drift ${ }^{14}$ ) is a necessary and sufficient explanation of observed traits.

- Educators also need to scaffold observation into how novelty begets novelty. New phenotypic forms or behaviors lead to (and are produced by) new types of ecological relationships, so a web of difference may be visible. In addition, the ways an ecological disturbance, such as the spread of an invasive species in an area, creates a rapid cascade of corresponding shifts among interacting organisms, would be a suitable area for naturalistic investigation. Inherited niches may also be considered.

- Educators can also take advantage of opportunities to foster interdisciplinary learning (IDL). For instance, a number of important mathematical concepts are deeply connected with observing and learning about the phenotypic plasticity of organisms. For example, some plasticity might not involve the development of a qualitatively novel trait but instead a rate of change at which some behavior occurs. Often, rates of change can really only be seen by plotting on a coordinate system against time.

- There are sometimes very interesting and abrupt "phase transitions" between behaviors or in the development of a new trait (West-Eberhard 2003). For example, just like a horse can increase its pace through trotting but at a crucial point shifts into a gallop, quantitative increases in the biological world lead to qualitative changes at threshold points. At such points, the dynamic relationship between the parts of the organism is re-coordinated by the context of the system as a whole (see discussion of reciprocal causation above). It is important to understand that the parameters and variables governing a living organism are only valid within a certain range of conditions, and so mechanistic interpretations are always only locally applicable. Seeking out phase transitions in the development and behavior of organisms points students to the limits of explanatory mechanism as a methodology in biology, with broader benefits for sustainability education, as discussed in the next section.

- There are opportunities to cultivate empathy as a scientific approach to engaging with organisms as adaptive subjects. This point will be explored further in the next section.

\footnotetext{
${ }^{14}$ Genetic drift (Wright 1948) is the process where the genetic composition of a population gradually changes over time owing to the chance intergenerational proliferation and disappearance of genes. It is a well-described phenomenon within the MS and features prominently in school curricula. In my experience, it captures little of the imagination and explanatory labor of the average educator, however prevalent it may be. While antagonistic in spirit to doctrinaire adaptationism, it still denies the causal agency of the organism in the evolutionary process.
} 


\section{Why New Conceptions of Evolution Matter for Sustainability Education}

Over the last decades in particular, there has emerged a need for an interconnecting meta-paradigm that integrates more strictly evolutionary studies, biodiversity studies and the ethical frameworks that are most appropriate for allowing a lasting coevolution between natural and social systems. Today such a need is more than a mere luxury, it is an epistemological and practical necessity. (Bergandi 2013, p. 1)

At this point, it is worthwhile to take a step back and examine why these alternative evolutionary explanations matter outside of being fascinating intellectual pursuits. Here, I hope to briefly convey two advantages for sustainability education that arise from challenging the ubiquitous reliance on MS explanations. The first concerns the way we understand and respond to organisms adapting to a rapidly changing world. The second concerns the need and benefits of fostering empathetic attention to adaptive subjects around us.

The ontological shift from genes to organisms as agents in evolution is accompanied by the methodological shift from modeling generality to understanding particularity. Focus on common patterns and statistical generality has favored certain types of insights about nature over others. Biology is dominated by the method that seeks to "keep the type in mind and leave the single case, with all its accidents, alone" (Wentworth Thompson 1917, p. 271). Much of the rationale for outdoor learning with respect to evolutionary theory is to counteract some of the theoretical assumptions this approach has helped carve in scientists' minds. While the fact that species are composed of unique individuals accommodating and altering their environments can be taught in the classroom, the diverse and rich ways individual organisms do so is best experienced, and the best place to do this is in the field. If the accident-or "token" in philosophical language-is as important as the "type," then we need to consider the organism within its environment. In some fields such as psychiatry, the distinction between token and type has led to two different approaches to research, sometimes labelled idiographic and nomothetic (Windelband and Oakes [1894]1980). I have explored elsewhere the relationship between these two ways of thinking and the need to integrate them (Affifi 2019a, b). As this article has suggested, the unique attributes of "tokens" are often not accidental.

First, incorporating idiographic approaches suggested by these new theories of evolution can lead to a more responsive attitude towards the ecological crisis. Because species' behavior can change more dramatically over time than a gene-centered view of evolution would predict, we cannot presume a given species, invasive or otherwise, is necessarily expected to simply fulfil pre-established ecological roles in unvarying (or very slowly varying) ways. Opening awareness to this fact has important implications for reconstructing conservation and resource management. On the one hand, it implies conservationists need to appreciate organismic agency in their models and management plans. More broadly, it suggests ecological management is not only a profession but a universal dimension of human experience everyone must take more responsibility for. All humans are engaged in niche construction, be it through consumption, in their workplaces, or in their households. It is incumbent upon educators to prepare students to engage in niche construction with sensitivity and responsiveness, recognizing that each person's environment is itself also populated with sensitive and responsive niche-constructing beings.

As organisms negotiate changing climates, novel chemicals, and plastics, and otherwise altered habitats and resources, we should expect an increase in the kinds of novel responses discussed in this article. These may be observable as phenotypic structural changes, as novel ecological behaviors, or as a combination of both. Learning to see these changes is not merely about understanding how evolution works, but about gaining a better understanding of how the biosphere is adapting — and failing to adapt - to anthropogenic threats. Sustainability education should therefore foster an attitude amongst both future scientists and the general public (and perhaps "citizen scientists") that seeks to understand and articulate such changes, which consequently can inform more responsive management decisions. This is a far cry from typical natural history guides and surveys (e.g., Open Air Laboratories (OPAL) citizen scientist surveys in the UK), which focus on identifying species' typical organisms and their niches. Through this work, we may see some of the creative reconstruction life undergoes in the face of disturbance. This may provide a hopeful antidote to the gloomy scenarios predicted by evolutionary models that conceive organisms as fixed products of past selection and uniquely fit for very specific contexts disintegrating all around them. Creative response is all around us. However, it may not be quick enough for the scale and speed of the destruction, so the ontological shift indicated in this article does not imply we do not urgently need to protect existing habitats.

Second, experiential understanding of particular organisms has the potential to stimulate the affective dimension of ecology. There is growing evidence "time in nature" has a significant impact on learners' care for organisms and habitats, and a sustainability orientation (Chen-Hsuan Cheng and Monroe 2012; Christie and Higgins 2012; Nazir and Pedretti 2016). This is a factor in the recent "Second Warning to Humanity" by Ripple et al., and over 15,000 scientist signatories (2017), where they offer a series of 13 urgent actions to stabilize and reverse biodiversity loss and climate 
change. One of these is "increasing outdoor nature education for children as well as the overall engagement of society in the appreciation of nature" (2017, p. 3).

We are accustomed to thinking of learning, subjectivity, agency, sentience, creativity, and innovation as unique human capacities in an otherwise giant biochemical machine. However, the marvels of the natural world are not merely aesthetic wonders nor simply great green devices fulfilling essential ecological services. They are the processes, products, and livelihoods of beings eking out an existence in a precarious world where they would scarcely fare well were they simply replaying a genetic tune in reaction to the contexts they inhabit. The evolutionary picture that foregrounds organisms as adaptive subjects restores continuity between humans and the rest of the biosphere. Both developmental plasticity theory and niche construction theory center the organism as a sensitive and responsive agent in development, ecology, and evolution.

Though naive anthropomorphism muddles the scientific aim of understanding phenomena, a commitment to avoiding it at all costs is equally naive (Smuts 2006; Affifi 2014). The failure to recognize that organism subjectivity organizes reciprocally causal relations in other species is a consequence of this over-extended dogma. What is needed is a way of imagining the point of view of other organisms that is neither a simple projection of human consciousness nor the reductive application of forms of causality that deny the ontological importance of the organism. I believe what is needed is a "relational empathy" that sees the development of a felt understanding of the other as an ongoing and fallible interactive process. Broome (1991) characterizes empathy as "a series of successive approximations to the other's point of view during social interaction" (p. 241). In its iterative engagement, empathy could be considered as something like a scientific approach to biological subjectivity in the sense described above. According to Godfrey-Smith's (2014) interpretation of Kerr, communication is a process where an organism alters its phenotype while changing its niche. Given the arguments above, this should be an obvious but uninformative point. The details make it interesting and relevant for the present discussion. Signals are an important feature of communication in the biological world. Signaling is a behavioral modification and hence a phenotypic change, and it alters the sender's environment through how it influences the receiver. On the other hand, receiving a signal also creates a phenotypic response, with consequences in turn for the receiver's environment. For example, as I come to see how walking across the courtyard in front of my office affects our local magpie, I slow or soften my gait. This in turn is responded to. The magpie no longer jumps away so swiftly, rather it cocks its head pointing an eye right at my face, giving me a further sense about the point of view of that bird. As is clear, empathy's "successive approximations" are not gearing into a stable and preexisting corvid subjectivity, but into a point of view unique to this being and at least in part the product of its ongoing interactions. "Getting a feel for another organism" (as McClintock put it (Keller 2000)) through sustained encounter inevitably leads to deeper understanding because one's ideas and hypotheses are contextualized by the broader understanding that develops. Those with keen empathy, and this includes many great naturalists, with Darwin himself at the forefront, employ this strategy and their success can be attributed to it (see Ireland 2009). It can be powerful scientifically but also has wide implications for sustainability education through how it can foster a next generation that is inquisitive, admiring, and caring for the diverse subjects co-creating the world.

Open Access This article is licensed under a Creative Commons Attribution 4.0 International License, which permits use, sharing, adaptation, distribution and reproduction in any medium or format, as long as you give appropriate credit to the original author(s) and the source, provide a link to the Creative Commons licence, and indicate if changes were made. The images or other third party material in this article are included in the article's Creative Commons licence, unless indicated otherwise in a credit line to the material. If material is not included in the article's Creative Commons licence and your intended use is not permitted by statutory regulation or exceeds the permitted use, you will need to obtain permission directly from the copyright holder. To view a copy of this licence, visit http://creativecommons.org/licenses/by/4.0/.

\section{References}

Affifi R (2011) What Weston's spider and my shorebirds might mean for Bateson's mind: some educational wanderings in interspecies curricula. Can J Environ Educ 16:46-58

Affifi R (2014) Biological pedagogy as concern for semiotic growth. Biosemiotics 7(1):73-88

Affifi R (2019a) Restoring realism: themes and variations. Environ Educ Res. https://doi.org/10.1080/13504622.2019.1699026

Affifi R (2019b) Between will and wildness in STEAM education. In: Burnard P, Colucci-Gray L (eds) Why science and art creativities matter: (re-)configuring STEAM for future-making education. Brill/Sense, Rotterdam, pp 79-99

Arthur W (2004) Biased embryos and evolution. Cambridge University Press, Cambridge

Avital E, Jablonka E (2000) Animal traditions: behavioural inheritance in evolution. Cambridge University Press, Cambridge

Badyaev AV, Uller T (2009) Parental effects in ecology and evolution: mechanisms, processes and implications. Philos Trans R Soc B 364:1169-1177

Bateson W (1894) Materials for the study of variation treated with especial regard to discontinuity in the origin of species. Macmillan, London

Bergandi D (2013) The structural links between ecology, evolution, and ethics: the virtuous epistemic circle. Springer, Dordrecht

Brandon R (1990) Adaptation and environment. Princeton University Press, Princeton 
Broome BJ (1991) Building shared meaning: implications of a relational approach to empathy for teaching intercultural communication. Commun Educ 40:235-249

Carroll S (2005) Endless forms most beautiful: the new science of Evo-Devo. Norton, New York

Chen-Hsuan Cheng J, Monroe MC (2012) Connection to nature: children's affective attitude toward nature. Environ Behav 44(1):31-49

Christie B, Higgins P (2012) The impact of outdoor learning experiences on attitudes to sustainability: a brief review of literature. Field Studies Council/University of Edinburgh. Field Studies Council Report 06/2012

Clark A (2006) Language, embodiment, and the cognitive niche. Trends Cognit Sci 10(8):370-374

Cock A, Forsdyke DR (2008) Treasure your exceptions: the science and life of William Bateson. Springer, Dordrecht

Creanza N, Feldman MW (2014) Complexity in models of cultural niche construction with selection and homophily. Proc Natl Acad Sci USA 111:10830-10837

Darwin C (1859) On the origin of species by means of natural selection. Murray, London

Davidson E (2006) The regulatory genome: gene regulatory networks in development and evolution. Academic Press, Cambridge

Dawkins R (1976) The selfish gene. Oxford University Press, Oxford

Dawkins R (1982) The extended phenotype. Oxford University Press, Oxford

Deacon T (2003) Multilevel selection in complex adaptive systems: the problem of language origins. In: Weber BH, Depew DJ (eds) Evolution and learning: the Baldwin effect reconsidered. MIT Press, Cambridge, pp 81-106

Dennett D (1995) Darwin's dangerous idea. Simon and Schuster, New York

Depew D, Weber B (2011) The fate of Darwinism: evolution after the modern synthesis. Biol Theory 6:89-102

Dewey J (1963) The reflex arc concept in psychology. In: Ratner J (ed) Philosophy, psychology, and social practice. Capricorn Books, New York

Dewey J (2005) Art and experience. Penguin Books, London

Fisher R (1918) The correlation between relatives on the supposition of Mendelian inheritance. Philos Trans R Soc Edinb 52:399-433

Gagliano M (2014) Experience teaches plants to learn faster and forget slower in environments where it matters. Oecologia 175(1):63-72

Gilbert S, Sapp J, Tauber AL (2012) A symbiotic view of life: we have never been individuals. Q Rev Biol 87(4):325-341

Gilbert S, Bosch TC, Ledon-Rettig C (2015) Eco-evo-devo: developmental symbiosis and developmental plasticity as evolutionary agents. Nat Rev Genet 16:611-622

Gissis SB, Jablonka E (eds) (2011) Transformations of lamarckism: from subtle fluids to molecular biology. MIT Press, Cambridge

Godfrey-Smith P (1996) Complexity and the function of mind in nature. Cambridge University Press, Cambridge

Godfrey-Smith P (2001) Three kinds of adaptationism. In: Orzack SH, Sober E (eds) Adaptationism and optimality. Cambridge University Press, Cambridge, pp 335-357

Godfrey-Smith P (2014) Philosophy of biology. Princeton University Press, Princeton

Godfrey-Smith P (2017) The subject as cause and effect of evolution. Interface Focus 7:1-10

Goldschmidt R (1940 [1982]) The material basis of evolution. Yale University Press, New Haven

Goodwin B (1997) How the leopard changed its spots. Scribner, New York
Gould SJ, Lewontin RC (1979) The spandrels of San Marco and the Panglossian Paradigm: a critique of the adaptationist programme. Proc R Soc Lond B 205:581-598

Gould SJ, Vrba ES (1982) Exaptation-a missing term in the science of form. Paleobiology 8(1):4-15

Griffiths PE (2008) In what sense does 'nothing make sense except in the light of evolution'? Acta Biotheor 57:11-32

Haldane JBS (1927) A mathematical theory of natural and artificial selection, part V: selection and mutation. Math Proc Cambridge Philos Soc 23(7):838-844

Hamilton WD (1964) The genetical evolution of social behaviour I. J Theor Biol 7:1-52

Ireland C (2009) Darwin's empathy, imagination highlighted. The Harvard Gazette (February 26, 2009). https://news.harvard.edu/ gazette/story/2009/02/darwins-empathy-imagination-highlighte d/. Accessed 15 Jan 2020

Jablonka E, Lamb M (1999) Epigenetic inheritance and evolution: the Lamarckian dimension. Oxford University Press, Oxford

Jablonka E, Lamb M (2005) Evolution in four dimensions. MIT Press, Cambridge

Jones CG, Lawton JH, Shachak M (1994) Organisms as ecosystem engineers. Oikos 69:373-386

Jones CG, Lawton JH, Shachak M (1997) Positive and negative effects of organisms as physical ecosystem engineers. Ecology 78:1946-1957

Juarrero A (1999) Dynamics in action: intentional behavior as a complex system. MIT Press, Cambridge

Kampourakis K (2013) Teaching about adaptation: why evolutionary history matters. Sci Educ 22:173-188

Keller EF (2000) A feeling for the organism, 10th anniversary edition: the life and work of Barbara McClintock. St. Martins Press, New York

Kerr B, Schwilk D, Bergman A, Feldman MW (1999) Rekindling an old flame: a haploid model for the evolution and impact of flammability in resprouting plants. Evol Ecol Res 1:807-833

Kirschner M, Gerhart J (2005) The plausibility of life: resolving Darwin's dilemma. Yale University Press, New Haven

Laland KN, Odling-Smee FJ, Feldman MW (1996) On the evolutionary consequences of niche construction. J Evol Biol 9:293-316

Laland KN, Odling-Smee FJ, Feldman MW (1999) Evolutionary consequences of niche construction and their implications for ecology. Proc Natl Acad Sci USA 96:10242-10247

Laland KN, Odling-Smee J, Gilbert SF (2008) EvoDevo and niche construction: building bridges. J Exp Zool B 310(7):549-566

Laland KN, Odling-Smee J, Hoppitt W, Uller T (2012) More on how and why: cause and effect in biology revisited. Biol Philos 28:719-745

Laland KN, Uller T, Feldman MW, Sterelny K, Müller GB, Moczek A et al (2015) The extending evolutionary synthesis: its structure, assumptions and predictions. Proc R Soc B 282:1-14

Laland KN, Mathews B, Feldman MW (2016) An introduction to niche construction theory. Evol Ecol 30:191-202

Lamarck J-B (1809) Philosophie Zoologique. Dentu et L'Auteur, Paris

Larson B (2014) Metaphors for environmental sustainability: redefining our relationship with nature. Yale University Press, New Haven

Lehrer R, Schauble L (2012) Seeding evolutionary thinking by engaging children in modeling its foundations. Sci Educ 96(4):701-724

Lewontin RC (1983) Gene, organism and environment. In: Bendall DS (ed) Evolution from molecules to men. Cambridge University Press, Cambridge, pp 273-286

Margulis L (1993) Symbiosis in cell evolution: microbial communities in the Archean and Proterozoic Eons, 2nd edn. Freeman, New York 
Mayr E (1974) Teleological and teleonomic, a new analysis. In: Cohen RS, Wartofsky MW (eds) Methodological and historical essays in the natural and social sciences. Boston studies in the philosophy of science, vol 14. Springer, Dordrecht, pp 133-150

Mayr E, Provine WB (1981) The evolutionary synthesis. Bull Am Acad Arts Sci 34(8): 17-32

McVaugh NK, Birchfield J, Lucero MM, Petrosino AJ (2011) Evolution education: seeing the forest for the trees and focusing our efforts on the teaching of evolution. Evol Educ Outreach 4(2):286-292

Moss L (2003) What genes can't do. MIT Press, Cambridge

Müller GB (2017) Why an extended evolutionary synthesis is necessary. Interface Focus 7(5):1-11

Müller GB, Newman S (eds) (2003) Origins of organismal form: beyond the gene in developmental and evolutionary biology. MIT Press, Cambridge

Nazir J, Pedretti E (2016) Educators' perceptions of bringing students to environmental consciousness through engaging outdoor experiences. Environ Educ Res 22(2):288304

Noble D (2015) Evolution beyond neo-Darwinism: a new conceptual framework. J Exp Biol 218(1):7-13

Nuutinen V (2010) The meek shall inherit the burrow: feedback in earthworm soil modification. In: Karaca A (ed) Biology of earthworms. Springer, Berlin, pp 123-140

Odling-Smee FJ (1988) Niche constructing phenotypes. In: Plotkin HC (ed) The role of behavior in evolution. MIT Press, Cambridge, pp 73-132

Odling-Smee FJ (2010) Niche inheritance. In: Pigliucci M, Müller G (eds) Evolution: the extended synthesis. MIT Press, Cambridge, pp 175-208

Odling-Smee FJ, Laland KN, Feldman MW (2003) Niche construction: the neglected process in evolution. Princeton University Press, Princeton

Oyama S (2000) The ontogeny of information. Duke University Press, Durham

Oyama S, Griffiths PE, Gray RD (eds) (2001) Cycles of contingency: developmental systems and evolution. MIT Press, Cambridge

Paley W (1809) Natural theology: or, evidences of the existence and attributes of the Deity, 12th edn. J. Faulder, London

Pigliucci M (2008) Is evolvability evolvable? Nat Rev Genet 9:75-82

Pigliucci M, Müller G (2010) The extended evolutionary synthesis. MIT Press, Cambridge

Ripple WJ, Wolf C, Newsome TM, Galetti M, Alamgir M, Crist E, 15,364 signatories et al (2017) World scientists' warning to humanity: a second notice. Bioscience 67(12):1026-1028. https ://doi.org/10.1093/biosci/bix125

Schlichting CD, Wund MA (2014) Phenotypic plasticity and epigenetic marking: an assessment of evidence for genetic accommodation. Evolution 68(3):656-672

Schmalhausen II ([1949]1986) Factors of evolution. University of Chicago Press, Chicago

Schwab DB, Moczek AP (2017) Evo-devo and niche construction. In: Müller G, Nuno de la Rosa L (eds) Evolutionary developmental biology. Springer, Dordrecht, pp 1-14
Shapiro J (2011) Evolution: a view from the 21st century. FT Press Science, Upper Saddle River

Skinner BF (1938) The behavior of organisms: an experimental analysis. Appleton-Century, New York

Smuts B (2006) Between species: science and subjectivity. Configurations 14(1-2):115-126

Stearns SC (1989) Trade-offs in life-history evolution. Funct Ecol 3:259-268

Thompson DW (1917) On growth and form. Cambridge University Press, Cambridge

Thompson E (2007) Mind in life. Harvard University Press, Cambridge

Tollefson H (2019) Humans are driving one million species to extinction. Nature 569(7755): 171

Turner JS (2000) The extended organism: the physiology of animalbuilt structures. MIT Press, Cambridge

Waddington CH (1953) Genetic assimilation of an acquired character. Evolution 7:118-126

Wagner A (2007) Robustness and evolvability in living systems. Princeton University Press, Princeton

Wagner GP, Altenberg L (1996) Perspective: complex adaptations and the evolution of evolvability. Evolution 50(3):967-976

Walsh D (2015) Organisms, agency and evolution. Cambridge University Press, Cambridge

Wentworth Thompson D (1942) On growth and form. Dover, New York

West-Eberhard MJ (2003) Developmental plasticity and evolution. Oxford University Press, Oxford

West-Eberhard MJ (2005) Developmental plasticity and the origin of species differences. Proc Natl Acad Sci USA 102:6543-6549

Williams GC (1992a) Natural selection: domains, levels, and challenges. Oxford University Press, New York

Williams GC (1992b) Gaia, nature worship, and biocentric fallacies. Q Rev Biol 67:479-486

Williams GC (1966) Adaptation and natural selection. Princeton University Press, Princeton

Wilson DS (2010) Multilevel selection and major transitions. In: Pigliucci M, Müller G (eds) Evolution: the extended synthesis. MIT Press, Cambridge, pp 81-94

Windelband W, Oakes G ([1894]1980) History and natural science. Hist Theory 19(2):165-168

Wright S (1932) The roles of mutation, inbreeding, crossbreeding and selection in evolution. In: Proceedings of the 6th international congress on genetics 1, Ithaca, NY, pp 356-366

Wright $S$ (1948) On the roles of directed and random changes in gene frequency in the genetics of populations. Evolution 2(4):279-294

Publisher's Note Springer Nature remains neutral with regard to jurisdictional claims in published maps and institutional affiliations. 